\title{
Formulating and clarifying the research topic: insights and a guide for the production management research community
}

\author{
Daniel Wintersberger $^{\mathrm{a} *}$ (D), Mark Saunders ${ }^{\mathrm{a}}$ \\ aUniversity of Birmingham, Birmingham Business School, Birmingham, United Kingdom \\ *d.wintersberger@bham.ac.uk
}

\begin{abstract}
Paper aims: To provide guidance on formulating and clarifying research questions from abstract and broad ideas.

Originality: Reports of empirical research invariably offer limited insights on the opaque process of developing research questions, aims and objectives. Moreover, we are not aware of a similar discussion within this journal, as well as other management journals.
\end{abstract}

Research method: This is a theoretical paper.

Main findings: Among other factors, our discussion highlights the role of theory and self-reflection in the process of research topic refinement. We consider the nature and types of theoretical contribution a research project can make, highlighting some common reasons why journal submissions are often rejected due to failure to provide a theoretical contribution.

Implications for theory and practice: Greater reflexivity in this process should ultimately lead to clearer theoretical contributions and more manageable research topics, with greater practical and societal relevance.

Keywords

Research note. Research questions. Reflexivity. Research objectives.

How to cite this article: Wintersberger, D., \& Saunders, M. (2020). Formulating and clarifying the research topic: insights and a guide for the production management research community. Production, 30, e20200059. https://doi. org/10.1590/0103-6513.20200059.

Received: Jun. 21, 2020; Accepted: Sep. 08, 2020.

\section{Introduction}

Building on existing methodological contributions to this journal (Nakano \& Muniz Junior, 2018; Mello et al., 2012; Miguel, 2007), the aim of this research note is to offer the production management community a guide to an, often unreported aspect of research methods: formulating and clarifying the research topic. While it is acknowledged that a good research project has a clear research question, aim and objectives, the process we undergo to get to this point from our initial thoughts about a possible topic is reported rarely. Rather, studies are presented in their finalised form. Given the process of formulating the research topic is likely to be iterative, characterised by the developing, clarifying, and re-formulating research ideas, it is unlikely to be straightforward (Saunders et al., 2019). Yet, although it is time-consuming and can be frustrating, time spent on developing, clarifying and reformulating helps provide the essential base for a good research project.

We start this note by considering the initial formulating of a research topic, giving particular emphasis on developing the underlying rationale, and methodological justification. Within this we highlight the importance of 'self-reflection', being reflexive in recognising one's own potential pre-existing biases and predilections, before discussing what we feel are some of the key characteristics of a good research topic, including the notion of 'symmetry' of potential outcomes. Next, we discuss subsequent refining of a research topic to a research question, 
aim and objectives; and as part of a preliminary inquiry, incorporating subject experts' input. The role of theory including its nature, development and potential types of contribution research can make are then considered. We conclude with a summary of key aspects that help constitute a 'good' research topic.

\section{Initial formulation}

Saunders et al. (2019) distinguish two pathways to formulating a topic from a nascent idea: one rational and the other creative. If following the rational pathway, we ask ourselves a series of questions such as: what are my strengths and weaknesses and those of any collaborators?; where are the key gaps in the literature?; or which topics have attracted a lot of attention in the media lately? Often broader topics have to be refined to more specific topics (more on these processes later), but the rational pathway is likely to be a more linear process; such as reviewing the literature to identify gaps in knowledge about which we can generate more specific research questions. The more creative pathway is likely to be less linear, and might include the keeping of a notebook of possible ideas, as well discussions with peers or subject experts. Not surprisingly, the topic may not only be refined but also may change substantially as a result of discussions. Regardless of which pathway you choose, it is important to engage in critical self-reflection (more on this in the following section) prior to and during topic formulation. It is also helpful to consider existing reviews of the literature as a means of establishing what is already known about your topic and where there are gaps in knowledge. Spotting a gap in the literature however may not be sufficient as a gap may exist because research is not needed! Arguably the nature of and extent to which your research truly has the potential to generate a theoretical contribution is one of the most important criteria in the review process of journal article submissions. Indeed, the main reason for rejection of submissions to this journal has been a failure on the side of the authors to clearly establish a theoretical contribution (Nakano \& Muniz Junior, 2018).

With this in mind, we next discuss both the importance of critical reflection and reflexivity and the role of theory in generating a research topic, as well as different ways in which we can enhance the theoretical contribution of our research.

\subsection{Critical reflection and reflexivity}

In formulating our research topic, we invariably make decisions such as choosing a particular topic, research strategy, data collection and analysis techniques, and how to engage with those we are researching. Alongside clarity regarding the reasons for these decisions, it is also helpful to engage in critical self-reflection (Johnson $\&$ Duberley, 2003); considering our own potential biases and predilections and how these might be impacting on our decisions, and may be shaped by our social context and views held by our research subjects.

Objectivists adopt the assumptions of the natural scientist, believing that research can be undertaken in a value-free, detached manner. Yet, while objectivists believe we can test (deduct) or build (induct) theory based on our observation of objective facts, this belief is not shared by everyone. Subjectivists argue that social phenomena cannot simply be converted into "[...] theory neutral observational language" (Johnson \& Duberley, 2003, p. 1282). In other words, research is value bound and our interpretations of the meaning of human actions (behaviours, speech etc.) are to some extent subjective, different researchers attributing differing meanings to and offering explanations for what they observe. If we consider an unstructured interview, some would argue we need not only to understand participant's words literally, but also to understand them in that individual's own terms; relating to them and seeing the world through their eyes. Such empathic understanding of participants is likely to influence our ability to objectively write up our research as we may be affected by our participants' views. Hence, we need to be aware of the potential relationship between ourselves and the 'objects' of our research (Johnson \& Duberley, 2003). Such, reflexive practices are underpinned by questioning whether a researcher can truly objectively observe and report on social observations (Alvesson et al., 2008) without being influenced by and influencing their participants.

Reflecting on the way we, as researchers, may influence those we are researching is certainly important. However, an aspect that is often overlooked is the significance of 'identity management' and our 'emotional labour' which, as researchers we may have to engage in as a means of obtaining access to relevant sites and subjects. To obtain 'rich' data and genuine responses from our participants, it is often necessary to build rapport. To form stronger bonds and build trust, we as researchers may have to construct identities that we would not necessarily adopt in other circumstances. In a research note on the issue, Cassell (2005) discusses her own adapted persona in male dominated research contexts (such as furniture warehouses), tolerating statements which she would otherwise have challenged. Thus, we are often in a position of dependence on those from 
whom we collect data, and this can influence on our own behaviours, or potentially even our interpretations of the meaning of observed phenomena.

In undertaking research, we may well encounter situations where we are quite dependent on goodwill and our ability to form an, at least rudimentary emotional bond with those from who we collect data. Yet, 'over-immersion' in the research context can be considered by some a potential problem, particularly where the researcher is participating fully in what is being researched. There are similar issues if researching our own organisation or practice, particularly under circumstances where as an 'insider' in Labaree (2002), we are wellacquainted with our participants.

\section{2. 'Gap spotting' and problematisation}

When generating the research topic, we need to consider what potential contribution to knowledge the project is likely to make. Most organizational scholars are not going to generate a completely new theory. Rather, they generally work on adding to existing knowledge (Whetten, 1989, p. 492). Therefore, it is not surprising that articles published in management journals mostly feature research that 'finds new ways to investigate around existing theoretical perspectives', a method referred widely as 'gap spotting' (Alvesson \& Sandberg, 2011), rather than challenging the assumptions that underpin existing theoretical perspectives. Such an approach is likely to generate incremental change to existing theory, perhaps extending its scope or establishing limitations. An alternative is generating research questions through 'problematisation' of the underlying assumptions of existing theory (Alvesson \& Sandberg, 2011, p. 247).

'Gap-spotting' may entail a 'systematic literature review' of a topic (see Nakano \& Muniz Junior, 2018 for a comprehensive outline), and identifying under-explored areas in the literature or perhaps contexts where an established theory has not been tested (Alvesson \& Sandberg, 2011, p. 249; Whetten, 1989). Such an approach, while having the advantage of being fairly comprehensive, also has the inevitable downside of limiting creativity and intuition in the literature search, and restricting the scope to databases supporting keyword search (Nakano \& Muniz Junior, 2018, p. 3). 'Gap spotting' may also entail the adding of a variable to a conceptual model. However, whilst such approaches can generate interesting findings, they may provide only limited incremental theory development without clear understanding of the contextual relevance. For example, "[...] discovering that a mainstream personnel selection model has low predictive validity in a military setting does not by itself constitute a theoretical contribution" (Whetten, 1989, p. 493). The meaningful theoretical contribution is understanding why a particular anomaly exists in this particular setting. Testing a theory on factors facilitating employees' knowledge sharing across different cultural contexts, for example, could generate a theoretical contribution if for example cultural differences between the chosen countries are significant and we have a good justification for believing that these cultural differences will account for differences in employees' attitudes towards knowledge sharing. Whetten therefore suggests that "[...] it is preferable to investigate qualitative changes in the boundaries of a theory (applications under qualitatively different conditions), rather than mere quantitative expansions" (Whetten, 1989, p. 493). The theoretical contribution then becomes the understanding derived, rather than simply testing the range and scope of its applicability.

We now return to the challenge of generating research questions through problematising an existing theory's underlying assumptions, including the ideological underpinnings (Alvesson \& Sandberg, 2011). Critical self-reflection is particularly important with regard to questioning our underlying ideological and political assumptions, some arguing that we all have "[...] sets of beliefs and values that affect our judgements" (Lewis et al., 2003, p. 16). For example, the way in which we view (with optimism or scepticism) individual or bundles of Human Resource Management practices implemented by an organisation depends to a substantial extent on our role within the organisation (if applicable), our own frames of reference, and how we view the employment relationship. Contrast, for example, the unitarist perspective that all members of a work organisation share the same overarching common goal (e.g. that commercial success supersedes our own individual interests) with the pluralist perspective that an organisation is made up of distinctive groups (e.g. managers, workers, shareholders) all of whom have different and potentially, in some cases, conflicting and contradictory goals. The unitarist perspective maintains that conflict is something only introduced by troublemakers (Guest, 1987). In contrast, the pluralist perspective, in drawing on the work of Webb \& Webb (1902) views conflict between various interest groups in an organisation as somewhat inevitable. The Webbs were British socialist economists who challenged mainstream classical and neoclassical accounts of the employment relationship, and advocated a pluralist employment relations model that places the collective dimension of the employment relationship, hence trade unions at the forefront (see also: Farnham, 2008). Invariably, as a researcher, the way you view the employment relationship is likely to have an impact on your research design as well as your subsequent data and its interpretation. 
It is worth recognising that, alongside the theoretical contribution, the practical and societal impact of academic research is becoming increasingly important. We therefore also need to consider the potential practical implications that may emerge from our research. In most academic articles published in management journals, the 'discussion' section is likely to refer to some key practical implications of the findings, and may provide ideas you wish to explore further.

Having discussed the role of theory in generating a research topic, we now turn to the characteristics of a good research topic.

\subsection{Topic characteristics}

A good research topic is one that is likely to provide interesting and new insights and contributions to existing debates in the literature for your target audience. When formulating a research topic, it is important we ensure a 'symmetry of potential outcomes' meaning that the findings will be of similar value whatever we discover (Gill \& Johnson, 2010). In other words, the findings should allow for a meaningful discussion, even if they are not what we expected. Consider a research topic focusing on the role of employee age in predicting attitudes towards performance-based pay. Assume we have already reviewed the existing literature on the link between reward and performance, and consider that attitudes towards variable pay negatively correlate with age. However, this topic appears to be concerned with the relationship between the two variables; in other words how an employee's age actually influences their attitude towards variable pay. Now, imagine the findings do not demonstrate a clear link between age and variable pay. In this case, there would be little to discuss in the findings beyond stating that age does not appear to predict attitudes towards variable pay. We might speculate on other personal factors (e.g. personality traits) that may influence employee attitudes, but are unlikely to have collected data to test these assumptions. It is therefore important to define the research topic to allow us to offer an insightful discussion, regardless of the research findings. With this in mind, we now consider some of the ways in which we can refine our broad research ideas to more specific research question(s) aims and objectives.

\section{Subsequent refining}

An initial research topic will, invariably require refining, this usually resulting in a research question, an aim and objectives. It is likely that this process will involve a preliminary inquiry comprising a more focused literature search and, often, discussion with those (subject experts) who have knowledge and experience in the area of investigation. In the context of empirical research within organisations, it may be beneficial to engage in a period of 'shadowing' employees who are likely to be important to the research. Where contextual environmental factors are important but we have little prior knowledge of the research context (perhaps a particular industry or manufacturing operation), it is important to derive at least a rudimentary understanding of the organisation, including its systems and structures as well as its less visible and more opaque aspects of culture, such as people's deeply held beliefs and underlying assumptions. This also allows the suitability of the research question to the particular context to be evaluated.

It may be the case that we wish to refine our research ideas by collecting data from subject experts. Let's say for example that we have arranged interviews with ten production engineers in different manufacturing firms on the topic of technological changes in their plant. As researchers, we are likely to possess less complete knowledge regarding the context of the study than all ten engineers combined. Similarly, each individual engineer is unlikely to have sufficient overview and understanding of the topic beyond what is only relevant within their own particular context (i.e. their own production plant). We may therefore want to get the combined input of all subject experts we have access to in order to refine our research idea from a broad, more vague idea based on your interests and (limited) existing knowledge of the topic, and the context of the study in particular to a more specific topic that is more actionable. Brainstorming may be a good technique allowing you to refine your research topic by obtaining and evaluating experts' suggestions. Alternatively, the Delphi technique may be used to reach consensus and generate possible research questions (Paraskevas \& Saunders, 2012).

\subsection{Research questions}

Research questions are important as they clearly define our problem, and what the research is trying to find out. The extent to which we can draw clear conclusions from the findings will depend on how the research question has been formulated. The overarching research question is also known as a 'general research question'. 
Subsequently, we are likely to generate a set of more detailed 'research objectives'. It is important to note that for exploratory research, the research question is likely to be refined as data are collected and the precise focus of the study becomes clearer.

It is important to carefully consider the wording of the research question to ensure confidence that the outcome of the research is likely to provide a new contribution to knowledge, and is of relevance to the target audience; in our case, relevant to current debates within this journal and among the wider production community. A suitable question ought to link with existing knowledge and literature in the field, but should also have the potential to provide new insights into the topic being investigated (Rojon \& Saunders, 2012).

When formulating the research question, clarity is crucial. One of the criteria on which the success of our research will be evaluated is the extent to which the conclusions are derived clearly from the data collected; and the research question form the foundations for this. The research questions therefore need to specify the issue or problem being examined (this forms the basis of the potential practical implications of the study), and what the research seeks to find out, explain and answer (Saunders et al., 2019). It is important to be clear about your general research question, as this has implications for your research design.

Research questions can be descriptive, explanatory, exploratory or a combination of these. When developing your research question it is important to avoid over-relying on one that only prompts descriptive answers. Rather, the research question should be sufficiently open-ended to promote an explanation. Good explanatory research questions are therefore more likely to start with words or phrases such as 'why', 'in what ways', and 'to what extent'. Similarly, exploratory research questions tend to start with words such as 'how' or 'what', and as such are able to elicit a broad range of answers. It is important that research questions are not too simple and not too ambitious either.

\subsection{Aim and objectives}

Many researchers and organisations expect research to also have a clear aim and objectives. The aim specifies the overarching purpose of your research. It highlights the theoretical and empirical gaps will be addressed, in other words what we wish to find out. The research objectives operationalise your research question and aim. They specify how the study will be conducted in order to meet the research aim and answer the research question. Research objectives need to be easy to understand and follow. They also need to be interconnected insofar as they should provide clear steps for conducting the research from start to finish.

\subsection{Preliminary inquiry}

One of the ways in which we refine the research topic is by reviewing the literature. This is also known as a 'preliminary inquiry'. Inevitably, journal submissions have word count constraints. Therefore, the methods section of journal articles generally only describes the research methods and techniques used in the actual study, ignoring the messy, iterative process of refining the question. This makes it difficult for other scholars to understand quite how the author(s) actually went about refining their research idea and operationalising it into clear research question(s), aims and objectives (Saunders \& Lewis, 1997). Beyond searching the literature, a preliminary enquiry may well include up front informal discussions with subject experts as well as 'shadowing' members of an organisation who are likely to be important in your research (Saunders et al., 2019). Shadowing is particularly beneficial where a researcher may have little prior contextual knowledge about your research setting (see McDonald, 2005; Mello et al., 2012 for a broader discussion of 'action research').

Within the field of production engineering, it is possible that there is substantial managerial influence on the choice of topic by an organisation to whom one is affiliated. This poses some constraints (namely restrictions on the direction of the research) but also opportunities in the form of significant levels of management support, hence access to relevant respondents for the research. It may be the case that the topic proposed by your research partners or employing organisation is quite broad. In such instances, a delicate balance will need to be struck between meeting the organisation's needs and the research objectives, by perhaps focussing on isolating a particular area of the research, which you deem most suitable for contributing to theory.

Building on the earlier section, which discussed the role of theory in generating a research topic, we now consider the theoretical contribution, discussing first the nature of theory and how a theoretical contribution can be made. 


\section{The theoretical contribution}

The theoretical contribution is a crucial component of the research project. Earlier in this note, we discussed the role of theory in developing a research topic, highlighting the importance of challenging the underlying assumptions (problematisation) of existing bodies of theory. In this section we examine the nature of theory, how it is developed and the role research questions, the aim and objectives play in this. We also consider the nature of theoretical contribution an empirical research project can make.

\subsection{The nature of theory}

Theory can be defined as 'a systematic body of knowledge grounded in empirical evidence which can be used for explanatory or predictive purposes.' (Saunders et al., 2015, p. 37). It is about the development of concepts and their subsequent examination. Concepts are then integrated with observed facts in order to provide explanations and predict outcomes. Crucial to this, is the way in which cause and effect of an outcome are related, that is the issue of 'causality'. With regard to our empirical research, we need to be clear regarding what evidence we actually require in order to derive legitimate conclusions regarding the direction of causality (i.e. cause and effect relationship) between two variables (Pearl, 2009, p. xv). Consider the statement: 'When it rains, my neighbour's lawn as well as my lawn are wet'. From this, we can conclude that probably both our lawns will be wet when it rains. However, concluding 'it must be raining' if both lawns were wet, would not be valid as other factors (including them watering their lawn) may cause this. Here the direction of causality is crucial, allowing us to determine only that our lawns will be wet when it rains, rather than to infer rain because the lawn is wet.

Alongside the issue of causality, we may be interested in understanding the underlying reasons for relationships between variables. This is a more complex issue, and one unlikely to be sufficiently addressed through merely descriptive (i.e. 'what' and 'how') questions. For example, the question 'what is the relationship between employee job satisfaction and performance' may superficially be fairly simply answered. An occupational psychologist may address the question by measuring employee self-reported levels of job satisfaction, and correlating these with their own context-specific performance measures. It might be expected that the likely result of such an investigation is that the two are positively associated. This would be a valid conclusion, though in its own right is unlikely to make a sufficient contribution to theory. A second line of inquiry here would be to derive the direction of causality between the two. It may be intuitively concluded that higher levels of job satisfaction lead to higher levels of job performance. However, how can we be sure that it is not the other way round? Perhaps better job performance and higher perceived competence makes people happier? A third line of inquiry would then be whether or not there is really a clear relationship (or merely an association) between the two variables. After all, better job performance could for example be linked with higher pay levels, which might actually be the key predictor of levels of job satisfaction and as such, pay would in this case constitute a moderating or even mediating variable between the independent and outcome variable.

Once theory has been developed from such observations, it can be used to explain relationships and predict outcomes if any of the variables are changed. In the above case for example, we could proceed by looking at what happens to employee job satisfaction where pay is more closely linked to individual performance.

\subsection{Development}

Existing theory, usually published in academic literature, can inform research question development in several ways. Firstly, it is likely to support research questions with the potential to elicit an answer that provides some degree of theoretical explanation (i.e. implications for theory), rather than just a descriptive answer (e.g. performance increased but we don't really know why'). Debates in the literature also enable us to find out whether others have asked similar questions, and whether such investigations took place in comparable or quite different contexts to our own. Simply testing an existing theory in your own context in its own right does not necessarily constitute a theoretical contribution. Rather, explanation is needed as to why this particular context was chosen, its relevance, and the insights others could draw. Sometimes we may find a well-established body of theory on our chosen topic. This can help us to refine our research questions(s) and potentially provides a set of variables to investigate. Where this is not the case, we need to explore concepts in more detail, and determine the extent to which they apply in our own research context. A significant body of research related to the issue may exist outside our own discipline. For example, research on issues of inequality spans (among others) economics, sociology, political economy as well as psychology. However, each of these disciplines have quite distinctive methodological approaches to addressing and operationalising the issue of inequality. 
The research project will be designed either to develop new theory or to test an existing theory. Where ample prior research and a well-developed body of theory around your topic of interest already exists, we are more likely to adopt a clear theoretical position prior to devising the research question(s), aims, objectives and potentially hypotheses; in other words, adopting a deductive theory-testing approach. In contrast, where there is limited prior research, and hence scant existing theoretical contributions, we are more likely to conduct exploratory research; deriving theory from data collected and using an inductive theory-building approach. Many researchers move between theory and data, in effect combining deduction and induction in an abductive approach to theory building. This usually begins with observing a surprising fact with the moving between theory and data enabling a plausible account of how it could occur to be developed.

\subsection{Contribution}

Most researchers contribute incrementally, developing or adding to existing theory, although in some cases more profound theoretical contributions may emerge. Such 'grand theory' developments generally occur in the natural sciences, an example being Newton's theory of gravity. In contrast, the second level 'middle-range theory' although less ground-breaking, but may still transform the way in which we think about certain phenomena. Both Maslow's (1943) 'hierarchy of needs' or Herzberg's (1954) 'two-factor' theory of motivation are examples of such middle range theory. When first published, both offered employers new ways of thinking about the best way to elicit high performance from their employees; breaking with the tradition of Taylor's (1911) 'scientific management' which saw people as inherently lazy and motivated only by material reward as opposed to intrinsic motivators at work. However, in most cases, we will be concerned with so-called 'substantive' theory in our research. In other words, theory that is restricted to a particular research context, time and population (Saunders et al., 2019, p. 47). Therefore, for example, findings from an empirical study on the impact of variable pay on performance in a particular context are likely to have limited generalisability to other contexts, especially given that we know that higher variable pay generally only leads to better performance in certain contexts, notably where tasks are algorithmic and require relatively routine cognitive skills. Despite this, it is worth keeping in mind that all three potential theoretical contributions - grand, middle-range, and substantive - are hierarchical in terms of their capacity to change the way in which we think about the world. The closer we move to substantive theory, the more constrained we are in generalising our conclusions beyond our own study.

\section{Summary and key aspects to consider}

With this research note, we have shared our view on what constitutes a good research topic, indicating some key considerations during the early formulation and refinement process of the research question, aim and objectives. In this process, we have highlighted the importance of critical 'self-reflection' on one's underlying assumptions, and how these can shape our research perspective. We have also examined the role of theory in the development of a research topic, discussing the nature of different theoretical contributions, ranging from grand to substantive theory. The formulation of a 'good' research topic is rarely a neat, linear process, and therefore the aim of our research note was to not only 'prescribe' (i.e. a 'how to guide' on the development of a research topic), but also discuss some of the potential considerations that need to be taken, highlighting the iterative nature of the process. Recognising the challenges in this process hopefully can equip us with a more reflective approach in the formulation of our research questions, aims and objectives in the future.

\section{References}

Alvesson, M., \& Sandberg, J. (2011). Generating research questions through problematization. Academy of Management Review, 36(2), 247-271.

Alvesson, M., Hardy, C., \& Harley, B. (2008). Reflecting on reflexivity: reflexive textual practices in organization and management theory. Journal of Management Studies, 45(3), 480-501. http://dx.doi.org/10.1111/j.1467-6486.2007.00765.x.

Cassell, C. (2005). Creating the interviewer: identity work in the management research process. Qualitative Research, 5(2), 167-179. http://dx.doi.org/10.1177/1468794105050833.

Farnham, D. (2008). Beatrice and Sidney Webb and the intellectual origins of British industrial relations. Employee Relations, 30(5), 534-552. http://dx.doi.org/10.1108/01425450810888295.

Gill, J., \& Johnson, P. (2010). Research methods for managers (8th ed.). London: Sage.

Guest, D. E. (1987). Human resource management and industrial relations. Journal of Management Studies, 24(5), 503-521. http:// dx.doi.org/10.1111/j.1467-6486.1987.tb00460.x.

Herzberg, A. (1954). Motivation and personality. New York: Harper \& Row. 
Johnson, P., \& Duberley, J. (2003). Reflexivity in management research. Journal of Management Studies, 40(5), 1279-1303. http:// dx.doi.org/10.1111/1467-6486.00380.

Labaree, R. V. (2002). The risk of 'going observationalist': negotiating the hidden dilemmas of being an insider participant observer. Qualitative Research, 2(1), 97-122. http://dx.doi.org/10.1177/1468794102002001641.

Lewis, P., Thornhill, A., \& Saunders, M. (2003). Employee relations: understanding the employment relationship. Harlow: Pearson Education.

Maslow, A. H. (1943). A theory of human motivation. Psychological Review, 50(4), 370-396. http://dx.doi.org/10.1037/h0054346.

McDonald, S. (2005). 'Studying actions in context: a qualitative shadowing method for organizational research. Qualitative Research, 5(4), 455-473. http://dx.doi.org/10.1177/1468794105056923.

Mello, C. H. P., Turrioni, J. B., Xavier, A. F., \& Campos, D. F. (2012). Action research in production engineering: a structure proposal for its conduction. Production, 22(1), 1-13. http://dx.doi.org/10.1590/S0103-65132011005000056.

Miguel, P. A. C. (2007). Estudo de caso na engenharia de produção: estruturação e recomendações para sua condução. Production, 171), 216-229. http://dx.doi.org/10.1590/S0103-65132007000100015.

Nakano, D., \& Muniz Junior, J. (2018). Writing the literature review for empirical papers. Production, 28(0), e20170086. http://dx.doi. org/10.1590/0103-6513.20170086.

Paraskevas, A., \& Saunders, M. N. K. (2012). Beyond consensus: an alternative use of Delphi enquiry in hospitality research. International Journal of Contemporary Hospitality Management, 24(6), 907-924. http://dx.doi.org/10.1108/09596111211247236.

Pearl, J. (2009). Causality. Cambridge: Cambridge University Press. http://dx.doi.org/10.1017/CB09780511803161.

Rojon, C., \& Saunders, M. N. K. (2012). Formulating a convincing rationale for a research study. Coaching, 5(1), 55-61. http://dx.doi. org/10.1080/17521882.2011.648335.

Saunders, M. N. K., \& Lewis, P. (1997). Great ideas and blind alleys? A review of the literature on starting research. Management Learning, 28(3), 283-299. http://dx.doi.org/10.1177/1350507697283002.

Saunders, M. N. K., Gray, D. E., Tosey, P., \& Sadler-Smith, E. (2015). Concepts and theory building. In L. Anderson, J. Gold, J. Stewart \& R. Thorpe (Eds.), Professional doctorates in business and management (pp. 35-56). London: Sage. http://dx.doi. org/10.4135/9781473921412.n3.

Saunders, M. N. K., Lewis, P., \& Thornhill, A. (2019) Research methods for business students (8th ed). Harlow: Pearson.

Taylor, F. W. (1911). The principles of scientific management. New York: Harper \& Brothers.

Webb, S., \& Webb, B. (1902). Industrial democracy. London: Longmans, Green \& Co.

Whetten, D. (1989). What constitutes a theoretical contribution? Academy of Management Review, 14(4), 490-495. http://dx.doi. org/10.5465/amr.1989.4308371. 